\title{
Yellow poplar (Liriodendron tulipiferaL.)grown in Korea versus imported Eucalyptus globules as a raw material for kraft pulping
}

\author{
Mun-Sung Kim, Soo-Jeong Shin ${ }^{1 \dagger}$ and Jong-Moon Park ${ }^{1}$ \\ Received July 15, 2013; Received in revised form August 2, 2013; Accepted August 7, 2013
}

\begin{abstract}
Yellow poplar grown in Korea and imported eucalyptus were compared their kraft pulping characteristics and evaluated the replacing possibility of eucalyptus by yellow poplar. Difference between yellow poplar and eucalyptus were investigated in chemical composition and fiber morphology.

Yellow poplar kraft pulp resulted in the higher yield, longer fiber length and thicker fiber, and higher pulp strength than that of eucalyptus. More xylan survived in eucalyptus than yellow poplar during kraft pulping, which led to similar pulp yield even though polysaccharides in Eucalyptus was $4.5 \%$ less than in yellow poplar. Longer and thicker yellow poplar pulp fiber resulted in better beating response and pulp strength properties.
\end{abstract}

Keywords : kraft pulping, yellow poplar (Liriodendron tulipiferaL.), pulp strength

\section{Introduction}

Kraft pulping process has been developed as main chemical pulping process which have several advantage compared to other chemical process as using any wood species as pulping raw materials, relative simple process in chemical recovery compared with sulfite pulping process, and stronger pulp than other chemical pulping process. ${ }^{1-3)}$ Kraft pulping process is well known process as extractives removal during alkaline pulping process, which allows higher extractives containing wood as raw materials. Alkaline hydrolysis of triglycerides, steryl fatty acid ester ester generates fatty acid. Fatty acid in hardwood and fatty acid, resin acid in softwood serve as surfactant in alkaline pulping process for removal of hydrophobic extractives which is not soluble in aqueous reaction system.

Limitation of fossil fuels, and global warming from carbon dioxide accumulation led to more concerns in renewable energy sources. Woody biomass is top candidate for the replacement of fossil fuels with vast amount of availability and reproducible with proper

- Daehan Paper Co. 131-1 Ssangchong Kanwoe, Chongwon, Chungbuk, Korea 363-952

1 Wood and Paper Science, Chungbuk National University, Cheongju, Chungbuk, Korea 361-763

$\dagger$ 교신저자 (Corresponding Author: Soo-Jeong Shin) : E-mail:soojshin@cbnu.ac.kr 
forest management system.

In chemical pulp industry, secure of wood chip is one main concern in near future with competition for raw materials with bioenergy or biorefineries sector. More than $90 \%$ of wood chips for Korean chemical pulp mill are imported eucalyptus and the others are supplied by mixed Korean domestic chips. Replacement of imported eucalyptus by main Korean silvicultural wood species is important for secure raw material supply for domestic pulp production and market for yellow poplar growers. In 1925, yellow poplar was first introduced in Korea. Adjustability of yellow poplar in Korea was tested by Korean Forest Research Institute in 1970-1973 and selected top silvicultural wood species.

In previous work, soda-anthraquinone pulping characteristics of yellow poplar was reported, which had similar or better pulping characteristics compared with imported tropical mixed hardwood pulp. ${ }^{4}$ However, alkaline chemical pulping mill in South Korea have taken kraft pulping process. In this work, we investigated domestic grown yellow poplar as pulping raw material with focused on chemical composition, kraft pulping characteristics, fiber morphology, and pulp strength properties of yellow poplar fiber. Also, we investigated the possibility of replacement of eucalyptus wood chip with yellow poplar.

\section{Materials and Methods}

\subsection{Material}

Yellow poplar grown at Chungbuk National University campus(Cheongju, South Korea) was cut, debarked and chipped. Air-dried chips were carefully hand screened to remove the oversize chip. Eucalyptus chip were supplied by courtesy of local kraft pulp mill(Murim Pulp and Paper, Ulsan, South Korea).

\subsection{Methods:}

\subsubsection{Kraft pulping:}

Pulping conditions are listed in Table 1. Kraft pulps were produced by batch cooking with liquor circulation. A A 5:1 liquid to wood ratio, $15 \%$ effective alkali (on $\mathrm{Na}_{2} \mathrm{O}$ basis) on chips and $30 \%$ sulfidity were used. The time to reach the target temperature $\left(170{ }^{\circ} \mathrm{C}\right)$ was 90 min and the duration was 40 and $50 \mathrm{~min}$. Pulps were washed, disintegrated and screened and kept at refrigerator $\left(4{ }^{\circ} \mathrm{C}\right)$ for further works. Screened yield, reject content, kappa number were measure followed by TAPPI standard method.

\subsubsection{Pulp properties measurement:}

Pulp fiber properties were measured by BauerMcnett for fiber distribution ${ }^{5)}$ and by fiber morphology analyzer (from Morfi Labo (LB-01)) for fiber length and width.

Pulp beating was performed in Valley beater, the refining degree was varied in the range 710-190 ml CSF. The procedure for forming handsheets for physical tests of kraft pulp was performed according to TAPPI standard T205 sp-95 at an oven-dried basis weight of $60 \mathrm{~g} / \mathrm{m}^{2}$ of handsheets. Handsheets were conditioned at $23 \pm 1{ }^{\circ} \mathrm{C}$, relative humidity, $50 \pm 2 \%$ for pulp strength properties tests. Hounsfield tensile tester and Elmendorf type tearing testers were applied for tensile and tear tests.

\subsubsection{Chemical compositional analysis:}

For chemical analysis of wood chip, acetone extraction, hot-water extraction and Klason lignin content were measured by 40-60 mesh milled wood powder followed by TAPPI standard procedures. Carbohydrate compositional analysis was measured by acid hydrolysis and NMR spectroscopic analysis of acid hydrolyzate. ${ }^{6}$

\section{Results and Discussion}

Based on chemical composition analysis of eucalyptus 
Table 1. Chemical composition of yellow poplar and eucalyptus

\begin{tabular}{lcc} 
& & Unit as \% \\
\hline & Yellow poplar & Eucalyptus \\
\hline Acetone extracts (A) & 2.5 & 2.2 \\
Hot water extracts (H) & 14.0 & 12.1 \\
Klason lignin (L) & 17.5 & 24.2 \\
Polysaccharides (P) & 66.0 & 61.5 \\
\hline
\end{tabular}

$\mathrm{P}=100-\mathrm{A}-\mathrm{H}-\mathrm{L}$

and yellow poplar wood meal, eucalyptus has $6.7 \%$ higher lignin content and $4.5 \%$ lower polysaccharides content than yellow polar (in Table 1). The same pulping conditions, eucalyptus kraft pulps had higher reject content than those of yellow poplar. Kappa number and Klason lignin content in yellow polar pulps were higher than in eucalyptus pulps (in Table 2).

From carbohydrate compositional analysis by ${ }^{1} \mathrm{H}-\mathrm{NMR}$ spectroscopy, cellulose content was $1.8 \%$ higher in eucalyptus but xylan content was $6.3 \%$ higher in yellow poplar (in Table 3). After kraft pulping, near $85 \%$ of cellulose were survived but xylan survival was quite different between yellow poplar (55.3-56.1\%) and eucalyptus (66.1\%). Higher xylan survival in eucalyptus compensated the lower polysaccharide content in wood chip and kept a little lower (1.0-1.3\%) kraft pulp yield during kraft pulping process. Pulping variables affect retention of xylan in kraft pulps. For eucalyptus kraft pulps, lower active alkali charge led to more xylan retention. ${ }^{7}$

In fiber length measurement, length weighted average length was used in Table 5.

Kraft pulp from yellow poplar was longer and thicker fiber than eucalyptus. In average length weighted length, a yellow poplar pulp was $0.93 \mathrm{~mm}$, which is $0.19 \mathrm{~mm}$ longer than eucalyptus pulp. Average width was $27.80 \mu \mathrm{m}$ for yellow poplar fiber

Table 2. Pulping characteristics of yellow poplar and eucalyptus

\begin{tabular}{lcccc}
\hline & \multicolumn{2}{c}{ Yellow poplar } & \multicolumn{2}{c}{ Eucalyptus } \\
\cline { 2 - 5 } & 40 min cooked & 50 min cooked & 40 min cooked & 50 min cooked \\
\hline Screen yield (\%) & 51.8 & 51.0 & 50.8 & 49.7 \\
Rejects (\%) & 0.5 & 0.4 & 2.4 & 0.7 \\
Kappa number & 27.0 & 20.2 & 22.5 & 19.3 \\
Klason lignin (\%) & 2.3 & 1.7 & 1.1 & 1.0 \\
\hline
\end{tabular}

Table 3. Carbohydrate compositional analysis of wood and kraft pulps from yellow poplar and eucalyptus

\begin{tabular}{llccc}
\hline & & \multicolumn{3}{c}{ Carbohydrate in pulp } \\
\cline { 3 - 5 } & & Total (\%) & Cellulose (\%) & Xylan (\%) \\
\hline \multirow{3}{*}{ Yellow poplar } & uncooked & 66.0 & 42.3 & 23.7 \\
& 40 min-cooked & $49.5^{*}$ & 38.2 & 13.3 \\
& 50 min-cooked & $49.3^{*}$ & 36.1 & 13.1 \\
\hline \multirow{3}{*}{ Eucalyptus } & uncooked & 61.5 & 44.1 & 17.4 \\
& 40 min-cooked & $49.7^{*}$ & 38.2 & 11.5 \\
& 50 min cooked & $48.7^{*}$ & 37.2 & 11.5 \\
\hline
\end{tabular}

*: Based on wood chips

Table 4. Fiber length analysis of eucalyptus and yellow poplar kraft pulps (40 min cooked)

\begin{tabular}{lcc}
\hline & Eucalyptus & Yellow poplar \\
\hline Arithmetic average length $(\mathrm{mm})$ & 0.62 & 0.75 \\
Average length weighted in length $(\mathrm{mm})$ & 0.74 & 0.93 \\
Average width $(\mu \mathrm{m})$ & 18.57 & 27.80 \\
\hline
\end{tabular}


but $18.57 \mu \mathrm{m}$ for eucalyptus. Fiber length distributions are listed in Fig. 1.

Unbeaten fiber showed higher CSF freeness values for yellow poplar than eucalyptus fiber and this trend was kept until 10 min beating. However, increasing beating more than $20 \mathrm{~min}$, yellow poplar fiber showed lower CSF freeness values than eucalyptus fiber. More careful observation is needed beating time between 10 to 20 min. (in Fig. 2)

Longer fiber can positively contribute to pulp strength properties. In repeated recycling of mixed office waste paper and fiber fractionation study, longer fiber gave stronger pulp. ${ }^{8)}$ Longer fiber length in domestic yellow poplar pulp resulted in higher strength properties than imported eucalyptus pulp in Fig. 3. Yellow poplar kraft pulps had more xylan content than those of eucalyptus (in Table 3). More xylan content in pulp affect also strength properties. In selective xylan removal and sorption of xylan to spruce kraft pulp, more xylan in pulp affected strength properties of handsheet. ${ }^{9)}$ In glucuronoarabinoxylan to cellulose fiber surface adsorption study, more xylan adsorption led to increase tensile strength. ${ }^{10)}$ In pulping variables to different xylan retention in eucalyptus kraft pulps, xylan affected apparent sheet density. Also, higher uronic acid in pulps positely impacted on tear index. ${ }^{7}$

In European hardwood and eucalyptus chemical pulps comparison, birch had the highest tensile strength followed by poplar and beech pulps but eucalyptus pulp showed the lowest tensile strength. ${ }^{11)}$

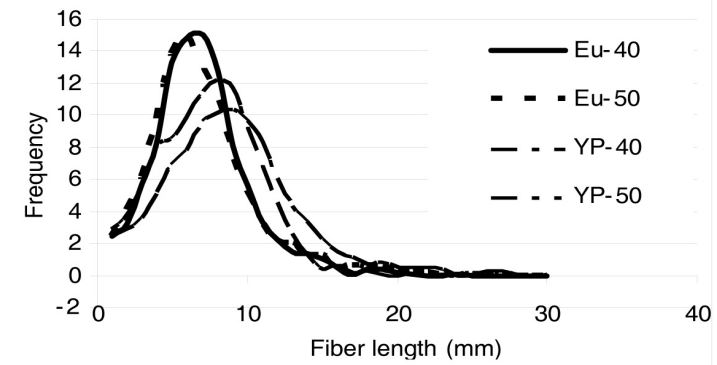

Fig 1. Different fiber morphology between yellow poplar and eucalyptus kraft pulps.

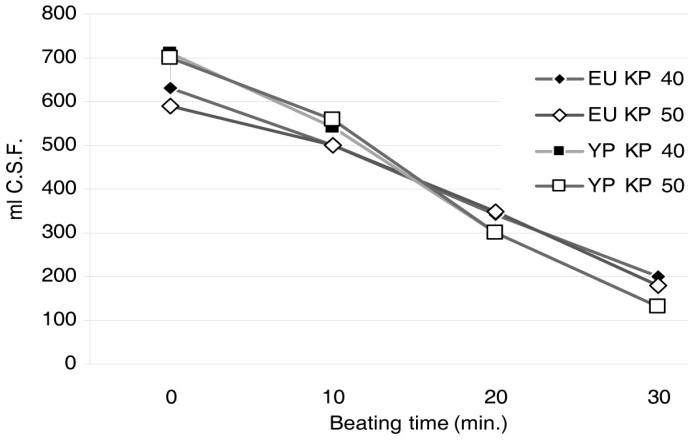

Fig 2. Different beating response between yellow poplar and eucalyptus.

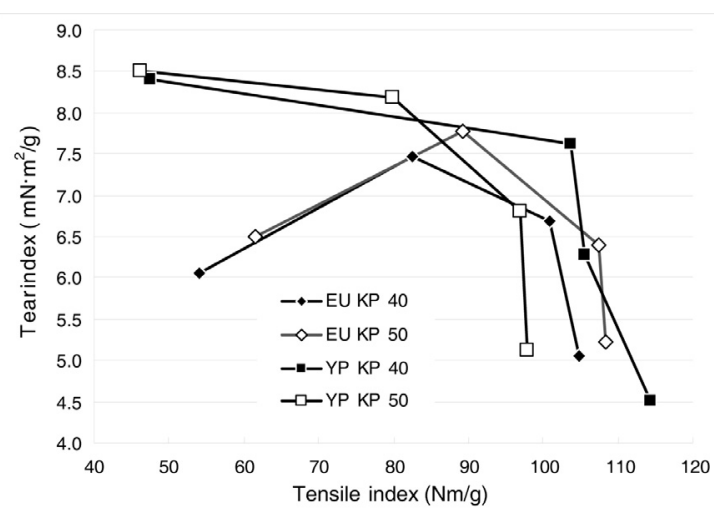

Fig 3. Pulp strength properties comparison between yellow poplar and eucalyptus.

Higher hemicelluloses content in alkaline sulfite, anthraquinone pulping process pulps led to higher tensile strength but lower tear strength kraft pulps. ${ }^{11)}$

\section{Conclusion}

Yellow poplar wood had higher xylan and lower lignin content than that of eucalyptus from chemical compositional analysis. However, easier delignification and higher xylan survival in eucalyptus reached closer this gap in xylan and lignin content in kraft pulps during kraft pulping.

Higher xylan content, longer and thicker fiber from yellow poplar led to easier response to beating and higher strength properties than those of eucalyptus. 
Therefore, it may be conclude that yellow poplar grown in Korea can successfully replace the eucalyptus for chemical pulp production.

\section{Literature cited}

1. Gierer, J., Chemical aspects of kraft pulping, Wood Sci. Technol. 14(4):241-266 (1980).

2. Chaka, F.S. and Ragauska, A.J., Review of current and future softwood kraft lignin process chemistry, Ind. Crops Prod. 20(2):131-141(2004).

3. Kleppe, P.J., Kraft pulping, TAPPI J. 53(1):35-47 (1970).

4. Sung, Y.J., Lee, J.-W., Kim, S.-B. and Shin, S.-J., Comparison of the soda-anthraquinone pulping properties between imported Eucalyptus mixture chips and domestic yellow poplar (Liriodendron tulipifera) chips, J. Korea TAPPI 42(3):22-27(2010).

5. Gooding, R.W and Olson, J.A.,Fractionation in a Bauer-McNett Classifier, J Pulp Pap. Sci. 27(12): 423-428(2001).

6. Shin, S.-J., Cho, N.-S., Conversion factors for carbo- hydrate analysis by hydrolysis and ${ }^{1} \mathrm{H}-\mathrm{NMR}$ spectroscopy, Cellulose 15: 255-260(2008).

7. Fardim, P., Duran, N., Retention of cellulose, xylan and lignin in kraft pulping of eucalyptus studied by multivariate data analysis: influences on physicochemical and mechanical properties of pulp. J. Braz. Chem. Soc. 15(4): 514-522(2004).

8. Abubakr, S., Scott, G.M., Klungness, J.H., Fiber fractionation as a method of improving handsheet properties after repeated recycling. Tappi J. 78(5): 123-126 (1995).

9. Schőnberg, C., Oksanen, T., Suurnäkki, H., Kettunen, H., Buchert, J., The importance of xylan for the strength properties of spruce kraft pulp fibres. Holzforschung 55(6): 639-644(2001).

10. Köhnke, T., Pujolras, C., Roubroeks, J. P., Gatenholm, P., The effect of barley husk arabinoxylan adsorption on the properties of cellulose fibres. Cellulose 15(4): 537-546(2008).

11. Patt, R., Kordsacchia, O., Fehr, J., European hardwood versus Eucalyptus globulus as a raw material for pulping. Wood Sci. Technol. 40: 39-48(2006). 